\title{
Justice: An elusive concept
}

Author:
Rik Torfs ${ }^{1}$
Affiliation:
'Faculty of Canon Law,
Katholieke Universiteit
Leuven, Leuven, Belgium
Corresponding author:
Rik Torfs,
rik.torfs@law.kuleuven.be
Dates:
Received: 04 Mar. 2020
Accepted: 29 Sept. 2020
Published: 21 Dec. 2020
How to cite this article:
Torfs, R., 2020, 'Justice:
An elusive concept', In
die Skriflig $54(1)$, a2612.
https://doi.org/10.4102/ids.
v54i1.2612
mobile device
to read online.
Copyright:
Read online:
Licensee: AOSIS. This work
is licensed under the
Creative Commons
Attribution License.

This article ventures to seek different approaches to the notion of 'justice'. It discusses John Rawls' interpretation of justice and concludes that, even within his famous definition, the notion of justice is not defined and merely raises further questions. Even in famous theories, such as those of Rawls, eventual value judgements about 'justice' cannot be avoided. Here, the approach of Celsus is preferred. His approach is also open to value judgements but does not pretend otherwise. This approach acknowledges that law is an art and does not pretend to have the ability to find a final definition of 'justice'. Within the more anthropological approach to law provided by Celsus, taking into account the context of culture and what its people perceive to be just, five points, of what Western Europeans perceive to be just are discussed namely - group rights, feelings, history, limited solidarity and the exception.

Keywords: Justice; Right; History; Solidarity; Lega exception.

What is justice? Some people seem to know the answer to this question, whilst others do not. Probably the latter have more wisdom. Let me try to explain.

When it comes to justice, two major approaches are possible. The first one is philosophical or ethical. The second is legal in the more profound sense of the word. The philosophical approach has been developed by many philosophers over the centuries. Yet in recent times, the influence of John Rawls (1921-2002) has been overwhelming. He published his famous book A Theory of Justice in 1971 (Rawls 1971). Ever since, philosophers in universities all over the world have been studying his ideas and have developed them further (Forrester 2019). Traditional metaphysical questions were left behind, to focus more than ever on the notion of justice. A notion which in previous times had been rather unexplored and remained a specific topic for lawyers and other people with a more pragmatic mind.

The key ideas of John Rawls (Rawls 1971) are well known. He starts with two principles. The first one sounds as follows: 'Each person is to have an equal right to the most extensive total system of equal basic liberties, compatible with a similar system of liberty for all'. The second principle tackles more concrete issues, at least at first glance (Rawls 1971):

Social and economic inequalities are to be arranged so that they are both (a) to the greatest benefit of the least advantaged, and (b) attached to offices and positions open to all under conditions of fair equality of opportunity. (p. 302)

To be honest, I have never been a fan of John Rawls, probably for two reasons. The first one is that I always preferred philosophers who do not leave aside truly metaphysical questions about the sense of life (although the end of metaphysics remains uncertain [Benoist 2004]). I admit this is a very personal and extrinsic argument. But I also have an intrinsic one, which goes as follows: John Rawls gives the impression to offer a crystal clear definition of what justice should be, whereas he actually only replaces the existing questions. Justice is hard to define in itself. Yet, the same is true for the notions he employs to explain the content of justice. What does he mean, for instance, by an extensive total system of basic liberties? How to work with a criterion such as the greatest benefit to the least advantaged? How to deal with fair equality of opportunity, without giving a value judgement on the notion of fairness? To put it bluntly, philosophers such as John Rawls do two things. On the one hand, they give the impression of offering a clear vision of what justice is. On the other hand, they replace the problem by introducing abstract notions that, in a later stage, can by themselves also be defined by again introducing new degrees of abstraction. The step to a concrete solution, without a value judgement that is not logically waterproof, can never be avoided. 
Personally, I prefer the second approach, which is at the same time much older and much simpler. It is the definition common to Roman lawyers, formulated amongst others by Publius Iuventius Celsus: 'Ius est ars aequi et boni' (Digesta 1.1.1). The law is the art of equity and goodness. The definition is shorter than the book by John Rawls, which makes it easier to put it on the wall of court buildings from Amsterdam to Hamburg or elsewhere. Similar to John Rawls, the definition is abstract. Indeed, how can goodness be defined? And who can give a description of equity that resists to all possible criticism? But there is one important difference between Celsus and Rawls. Whereas the philosopher John Rawls pretends to give a 'scientific' definition, the lawyer Celsus sees himself more as an artist: ius est ars. Law is an art. Let us not underestimate the methodological differences between the two approaches (Bagnall 1996). The approach by Rawls is driven by the underlying idea that ultimately the right definition of justice can be found. Maybe it takes time, perhaps circumstances can lead to some variations. But ultimately, we can come closer and closer to a purified notion of what justice truly is. One could argue that progress is behind this project: a world view implying the possibility of leaving behind the errors of the past. The vision by Celsus and Roman law is considerably more sophisticated, as art never arrives at its ultimate realisation. One can even argue that the accomplishment of justice, seen from a more 'artistic' perspective, is at the same time its failure. Indeed, the notion of established art is in itself a negation of artistic creativity, because the latter is inspired by continuous renewal based upon the reading of the signs of the times. One can refer here to the French artistic world in the 19th century whereby the official organisers of the annual Salon prohibited impressionist painters from participating because they did not fulfil the dominant artistic criteria (Crespelle 1981). They did not follow those criteria, just because they were artists. Compared with John Rawls, one can see Celsus as a person who does not believe in continuous progress, but in the strength or weakness of anthropology. Knowledge of justice turns out to be impossible without a notion of the question of who man truly is.

You may have noticed that my preference goes to Celsus. His more anthropological vision of law gives a lot of space to hermeneutic insights, taking into account the context of the current culture and its influence on what people perceive to be just. Starting from that angle, I would like to discuss five points which, in my eyes, are characteristics of what Europeans perceive to be just, right and fair. Perhaps I should say 'citizens of Western Europe', as the Central and Eastern part of the continent, probably as a result of a more recent totalitarian and communist experience, is less open to certain forms of more experimental thinking, typically coming from the United States.

\section{Group rights}

A first remarkable phenomenon is the strong revival of group rights (Bisaz 2012), even at the expense of the individual rights and freedoms. These individual rights very clearly lie on the basis of the Universal Declaration of Human Rights of 1948. Article 2 of the Declaration does not leave any doubt about that principle:

Everyone is entitled to all the rights and freedoms set forth in this declaration, without distinction of any kind, such as race, colour, sex, language, religion, political or other opinion, national or social origin, property, birth or other status. Furthermore, no distinction shall be made on the basis of the political, jurisdictional, or international status of the country or territory to which a person belongs, whether it be independent, trust, non-self-governing, or under any limitation of sovereignty. (art. 2)

The Article was formulated in a very specific era, immediately after World War II, a period of both war and totalitarian thinking. At the same time, many countries were still colonies or not independent yet. But the rights of those people were not forgotten. Amongst the authors of the Universal Declaration, the role of P.C. Chang from China was in that regard of utmost importance (Roth 2018). The underlying idea was always clear. The individual is more important than the group. No surprise about this, as in the Nazi regime groups were often the victims, whether they were Jews, gypsies or homosexuals. Today, however, belonging to a group becomes, at least in Western Europe, more important again. Positive discrimination for women, although legally not always easy to justify in the light of fundamental rights, became increasingly popular. Yet also other criteria mentioned explicitly in Article 2 of the Declaration are sometimes the object of positive or negative discrimination. Sometimes the political aim of fostering diversity in society prevails over individual rights of people. Positive discrimination on racial grounds is at this moment more of an issue in the United States than in Europe, but the idea of compensation for the colonial past also lives in Western Europe (Torfs 2018). Religion became quite an issue too, as many European politicians insist on the ('aggressive') neutrality of the state by forbidding religious signs in public life. Recently, a religious sister in Vesoul, France, was not admitted in a state-run home for the elderly because she refused to take off her religious habit (La Croix 19 November 2019). In short, political goals and group aspirations make individual rights weaker than they were meant to be at the moment of the promulgation of the Declaration in 1948.

\section{Feelings}

A rather recent phenomenon is the emergence of the role of feelings in the legal discussion on justice and fairness (ed. Ghelfi 2015). Two examples can illustrate this point.

The first one concerns the extension of the definition of religious freedom. For example, this happened in a decision of the European Court of Human Rights, E.S. vs. Austria of 25 October 2018. ${ }^{1}$ In this decision, the conviction in Austria of a person who had publicly stated that the prophet Mohammed was guilty of paedophilia was upheld by

1.Judgement by the European Court of Human Rights, Fifth Section, case of E.S. vs. Austria, Application nos. 38450/12, 25 October 2018. 
the European Court mainly because the feelings of many faithful were deeply hurt. Moreover, the opinion expressed did 'not contribute in an objective manner to a debate of public interest'. Traditionally, freedom of religion has three components, namely the individual freedom, the collective freedom to worship together and the freedom of internal organisation. This gives religions the opportunity to organise themselves along the lines of their doctrine as long as they are not transgressing public order.

Yet, apparently, a fourth element is gaining ground, namely the right not to be hurt. This is a remarkable evolution, and one can consider it as a re-introduction of the crime of blasphemy of the past. A specific aspect of this evolution is the legal relevance of feelings when it comes to defining the content of freedom of religion as well as the limit of freedom of expression. Indeed, some people feel hurt easily, whereas others are perfectly able to live with a lot of criticism. An additional element is that people who feel hurt may not be directly involved themselves. Not their person but certain concepts of their religion is under attack.

Traditionally, the rights of others are a limitation to human rights. Yet today, the feelings of others seem to form that border. This is a very dangerous evolution for human rights as a whole.

A second example of the growing influence of feelings is the idea of safe spaces, a phenomenon better known in the United States than in Western Europe, yet quickly gaining ground in Western European countries. The phenomenon is particularly seen in American universities, where the idea is that feelings of vulnerable students or students belonging to minorities, only those two categories, should never be shocked (Prager \& Joseph 2019). They have the right to be confronted only with ideas that are generally admitted and that reassure them in their personal convictions. As a result, certain lectures on controversial issues are no longer allowed to take place within the walls of the university. ${ }^{2}$ It goes without saying that such an approach is at odds with the traditional idea of a university, a place where debate is open, and any idea can be defended as long as norms of fairness and fair play are respected. This is also because universities are under pressure to train people for the job market - rather than searching for better understanding. Another example in line with this evolution is a peculiar incident at Cambridge University in the United Kingdom, where a copy of a painting by the 17th century Flemish artist Frans Snijders (1579-1657) was removed from the dining hall because it represented hunted and killed animals and thus shocked the feelings of pious vegetarians who were confronted with it on a daily basis (The Telegraph 21 November 2019).

\section{History}

When the Universal Declaration of Human Rights was promulgated in 1948, the hardly hidden underlying idea was

2.A certain number of academics support this idea. According to Ulich Bear (2019) free speech can serve as a hollow concept to advance a reactionary agenda rathe than set all of us free. that the past was the past and that we should look to the future to avoid the same mistakes being committed again. In other words, it was a kind of tabula rasa. Yet today, history is playing a role again. One of the elements is the idea of compensating injustices of the past by granting so-called 'justice' to people of the same category today. One could call this the theory of postponed sorrow (Torfs 2018). An example can illustrate this.

For a long time, in Western Europe, as in many other countries, women were discriminated against. They were not allowed to study at university or were excluded from voting in elections. These obstacles were removed only gradually, and the struggle for equal chances took many decades. Yet today, the theory of postponed sorrow claims advantages for women as a compensation for the sorrow undergone by their grandmothers. Historical discrimination is an argument for reverse discrimination as a compensation today. Of course, there may be arguments for this. But here again we see that the group becomes more important than the individual. Indeed, it is not the grandmother who receives compensation, as she will have most likely passed away. Another person obtains the reverse discrimination as a compensation for sorrow suffered by others belonging to the same group, in this case, the rather large and very diverse group of women. An interesting question remains: from what point onwards does this reverse discrimination creates new forms of injustice, possibly in need of a correction in a far future (Starck 2015)?

In any case, the role of history, absent as a legal criterion in 1948, becomes increasingly prominent today. This leads to an additional difficulty, as history as such is not a static notion and tends to change at any moment, sometimes unexpectedly. According to the Italian historian Benedetto Croce (1866-1952), all history is contemporary history, as all study of the past is coloured by the problems and needs of the writer's own time (Galasso 2002). As a result of that, every generation rewrites history. The wise words of Benedetto Croce are certainly true. Yet every generation also has the implicit idea that its version of history is an improvement over the previous one and may even be the ultimate interpretation. This is of course untrue. Yet, if we combine the tendency to take into account history to achieve justice, and the idea of history being a changing science, it is clear that a historical approach with regard to rights and justice is always a dangerous one ${ }^{3}$.

\section{Limited solidarity}

The tendency of limited solidarity differs somewhat from the previous ones and is more connected to the very procedural form of justice that is increasingly present in Western European societies. Here, two elements come together.

The first element is the welfare state (Spicker 2000). In the welfare state, which was already partially developed in

3.This is also a burning issue in a country like South Africa where even relief given by the government in times of a disaster may be subjected to this blanket form of justice as a criterion to who may receive help and who not. 
the interbellum but flourished after World War II, personal solidarity and charity are replaced by a legal system that ensures social security to all people. Healthcare, retirement pensions, unemployment benefits and schooling are all offered by the state. Financing all this requires high taxes but at the same time the solidarity remains anonymous. A citizen can pay high contributions without knowing exactly what happens with the money collected and even without having any interest in the beneficiaries of the social security system. He may even be firmly opposed to it. On the one hand, this evolution is a success because nobody is left behind. People are no longer dependent on uncertain charity and also less attractive people can enjoy these benefits. However, the system also has a negative point, namely the possibility of establishing a system of solidarity without any feeling of solidarity present amongst the citizens. In the long run, this may be harmful to the sustainability of the system (Deeming 2017).

A second element which goes hand in hand with the previous one is the growing influence of compliance systems in society as a whole, including in personal contacts and working situations. The obligation to follow adequate procedures becomes more important than making ethical value judgements and expressing personal feelings of sympathy or commitment, putting control before care. In many cases, ethical norms become procedural norms, not leading to deeper thinking but replacing thinking by a compliance procedure that seldom goes beyond the level of pure formalism.

The combination of abstract solidarity and formal compliance leads to a limited feeling of compassion and commitment when it comes to the suffering or the problems of other people. This becomes very clear in the current debate on migration in Western Europe. Whereas the distinction between a refugee and a migrant is still made in the technical sense, the support for the migrant population as a whole is quickly decreasing. This evolution goes together with a rapid growth of political parties carrying more extreme ideas. It goes without saying that the democratic state and the rule of law, including the respect of fundamental rights, should be preserved at any price. But then again, fundamental questions on what is just and what is right cannot be avoided any longer. One question concerns the limits of both solidarity and hospitality. Both are not unlimited (Derrida \& Defourmentelle 1997). ${ }^{4}$ One feels more solidarity with one's own family, village, region than with people coming from remote countries with different cultures and standards. Also, the notion of hospitality is under pressure. Is hospitality limited in time? Moreover, how can Western European systems of social security survive if many migrants who never contributed to it nonetheless qualify for its benefits?

4.According to Derrida, hospitality is theoretically limitless, yet not in practice (Derrida \& Defourmentelle 1997:144).
Here, two elements should be kept in mind. Firstly, human solidarity is limited and sooner or later it will be reflected in the legal system. Anthropology corrects abstract justice. Secondly, today we are confronted with different ideas of justice all over the world. The social welfare state as it exists today in Western Europe is hardly present in any other region worldwide. A combination of a regionally limited welfare state and (almost) free migration is impossible in the long run. An answer could lie in establishing welfare states everywhere or suppressing it in Western Europe. Yet, probably both are impossible or not desirable.

\section{The exception}

The fifth element that needs some attention is the exception (Sarfati 2016). We do not like it. We want a system characterised by equality. Moreover, in case we admit exceptions, we will never give it to an individual, we will always refer to the group. This lies at the heart of the difference between democracies and totalitarian states. The individual exception is not compatible with the idea of an abstract and formal approach, with the idea of a truly legal system.

A question remains whether some space should be left to the individual exception. It is a hazardous idea, as any exception to an abstract rule gives the impression of being unjust. The law is applicable to all. It is one of the main principles of our democratic legal system. A mechanic approach is also fostered by the growing influence of the Internet, strengthening uniformity and abstraction, and ultimately formatting human thinking. Nonetheless, in all languages, there are proverbs in favour of the exception. The exception confirms the rule is a saying we often hear. Its original meaning is that the presence of what is openly regarded as an exception and applies to a specific case confirms that a general rule exists.

In any case, the exception is at odds with the principle of equality. That is why, for instance in Roman Catholic canon law, privileges are looked at with distrust, and rightly so. A privilege implies that a person or a group of people are not bound by the law. Since the period of the Enlightenment, this strong form of inequality is no longer acceptable. But what about the individual exception? In canon law, it is called dispensation, which is meant to introduce one single exception for one single situation.

In general, people are opposed to the exception, at least theoretically. In practice, it is more difficult. For instance, people are sometimes very strict when it comes to repatriating migrants without a legal residence permit. Yet, when it comes to the neighbour or the classmate of their children, they may have a different opinion.

The exception to the rule may come close to what misericord used to be in the past or in legal tradition. At the same time, it does not fit within a system of abstract norms. Is there a solution for it in the future? Here, the answer is that as long 
as the trust is less important than compliance or the need to follow abstract norms, there is hardly any space for the exception, as people can only see abuse in it. Obviously, the difference between intrinsic justice and formal justice does not leave the space that the exception requires to be acceptable. For instance, a physical handicap or war circumstances may not be foreseen in formal procedures but could be relevant for a global value judgement underpinning the decision of allowing an exception.

\section{Conclusion}

To conclude, I do not believe in law as a closed or perfect system. Law is an art and does include both norms and a keen attention to anthropological concepts. Law always evolves but seldom makes progress. Today in Western Europe, the democratic state, the rule of law and the human rights catalogues are still absolutely crucial. The signs of the time can strengthen or can weaken them and probably they do both. I described five tendencies going from group rights, over the relevance of feelings to the power of history, the limited solidarity and the fear for the exception. New trends will emerge, and the current ones will not always lead to a satisfactory solution. Such is life. Such is law. Such is justice.

\section{Acknowledgements Competing interests}

The author declares that he has no financial or personal relationships that may have inappropriately influenced him in writing this article.

\section{Author's contribution}

R.T. is the sole author of this research article.

\section{Ethical considerations}

This article followed all ethical standards for research without direct contact with human or animal subjects.

\section{Funding information}

This research received no specific grant from any funding agency in the public, commercial or not-for-profit sectors.

\section{Data availability}

Data sharing is not applicable to this article as no new data were created or analysed in this study.

\section{Disclaimer}

The views and opinions expressed in this article are those of the author and do not necessarily reflect the official policy or position of any affiliated agency of the author.

\section{References}

Bagnall, G.P., 1996, Law as art, Routledge, London.

Benoist, J., 2004, 'Dépassement de la métaphysique', Revue philosophique de la France et de l'étranger 2004(2), 167-180. https://doi.org/10.3917/rphi.042.0167 Bisaz, C., 2012, The concept of group rights in international law, Brill/Nijhoff, Leiden. Crespelle, J., 1981, La vie quotidienne des impressionnistes 1863-1883, Hachette, Paris.

Deeming, C., 2017, 'The politics of (fractured) solidarity: A cross-national analysis of the class bases of the welfare state', Social Policy \& Administration 52(5), 1106-1125. https://doi.org/10.1111/spol.12323

De Neuville, H., 2019, 'A Vesoul, une religieuse refusée d'une maison de retraite en raison de son voile', La Croix, viewed n.d., from https://www.la-croix.com/ Religion/Laicite/religieuse-refoulee-dune-maison-retraite-causevoile-2019-11-19-1201061413.

Derrida, J. \& Defourmentelle, A., 1997, De l'hospitalité, Calmann-Lévy, Paris.

Forrester, K., 2019, In the shadow of justice: Postwar liberalism and the remaking of political philosophy, Princeton University Press, Princeton, NJ.

Galasso, G., 2002, Croce e lo spirito del suo tempo, Laterzo e Figli, Rome.

Ghelfi, F. (ed.), 2015, Le droit et les sentiments, L'Harmattan, Paris.

Prager, D. \& Joseph, M. (eds.), 2019, No safe spaces, Regnery Publishing, Washington, DC. Rawls, J., 1971, A theory of justice, Harvard University Press, Cambridge, MA.

Roth, H.I., 2018, P.C. Chang and the universal declaration of human rights, University of Pennsylvania Press, Philadelphia, PA.

Sarfati, J., 2016, Le rôle créateur de l'exception en droit, Connaissances et Savoirs, Paris.

Singh, A., 2019, 'Cambridge University students cry fowl over 17th century painting that upsets vegetarians', The Telegraph, viewed n.d., from https://www.telegraph.co.uk/ news/2019/11/21/cambridge-university-students-cry-fowl-17th-century-painting/.

Spicker, P., 2000, The welfare state: A general theory, Sage, London.

Starck, H., 2015, Positive Diskriminierung? Vor- und Nachteile der Gesetzlichen Frauenquote für Führungspositionen, Grin, London.

Torfs, R., 2018, Kardinale deugden. Een inleiding tot het moderne leven, Polis, Antwerp. 